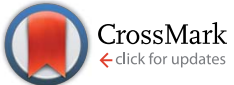

Cite this: RSC Adv., 2016, 6, 92655

\title{
One-step approach for preparing ozone gas sensors based on hierarchical $\mathrm{NiCO}_{2} \mathrm{O}_{4}$ structures $\uparrow$
}

\author{
Nirav Joshi, ${ }^{* a}$ Luís F. da Silva, ${ }^{\mathrm{b}}$ Harsharaj Jadhav, ${ }^{\mathrm{c}}$ Jean-Claude M'Peko, ${ }^{\mathrm{a}}$ \\ Bruno Bassi Millan Torres, ${ }^{a}$ Khalifa Aguir, ${ }^{d}$ Valmor R. Mastelaro ${ }^{a}$ \\ and Osvaldo N. Oliveira $\mathrm{Jr}^{\mathrm{a}}$
}

Nanostructured semiconducting oxides have been used as resistive gas sensors of toxic and non-toxic gases, but little emphasis has been placed on ozone sensing. Here we present a new ozone gas sensor based on hierarchical $\mathrm{NiCO}_{2} \mathrm{O}_{4}$ cubic structures synthesized via a facile urea-assisted co-precipitation method and annealed at $450{ }^{\circ} \mathrm{C}$, which showed a low detection level. Ozone detection was carried out through electrical measurements with an optimized performance at $200{ }^{\circ} \mathrm{C}$, with fast response $(\sim 32 \mathrm{~s})$ and recovery ( $60 \mathrm{~s}$ ) time with suitable concentration range (from 28 to $165 \mathrm{ppb}$ ) for technological applications. Furthermore, $\mathrm{NiCO}_{2} \mathrm{O}_{4}$ platelets are selective to ozone compared to other oxidizing and reducing gases. The low detection level can be attributed to the coexistence of 3D structures based on hexagonal platelet-like and porous flower-like shape, which were revealed by field emission scanning electron microscopy (FE-SEM). In summary, $\mathrm{NiCO}_{2} \mathrm{O}_{4}$ is promising for detection of sub-ppb levels of ozone gas.

Received 19th July 2016

Accepted 22nd September 2016

DOI: $10.1039 / \mathrm{c} 6 \mathrm{ra} 18384 \mathrm{k}$

www.rsc.org/advances therefore, the continuous monitoring of ozone levels is essential. ${ }^{19}$ Ozone gas sensors have been based on $\mathrm{ZnO}^{6}{ }^{6} \mathrm{In}_{2} \mathrm{O}_{3},{ }^{20}$ $\mathrm{SnO}_{2}$ (ref. 21) and $\mathrm{WO}_{3},{ }^{22} \alpha-\mathrm{Ag}_{2} \mathrm{WO}_{4},{ }^{23} \mathrm{SrTi}_{1-x} \mathrm{Fe}_{x} \mathrm{O}_{3}$ (ref. 24) which are suitable in terms of their operating temperature, selectivity, response, and stability. ${ }^{6}$

Ternary metal oxides can be even more useful owing to synergy in properties achieved by combining distinct compounds. Nickel cobalt oxide $\left(\mathrm{NiCo}_{2} \mathrm{O}_{4}\right)$ has such outstanding properties as high electrical conductivity, good structural stability, easy electrolyte penetration and high electrochemical activity. ${ }^{25}$ The preparation of $\mathrm{NiCo}_{2} \mathrm{O}_{4}$ has been accomplished using different routes, including solvothermal, ${ }^{26}$ co-precipitation ${ }^{27}$ and hydrothermal. ${ }^{28}$ These methods allow $\mathrm{NiCo}_{2} \mathrm{O}_{4}$ to be obtained in a variety of shapes, including flowers, nanowires, nanoarrays, nanorods, and hollow microspheres. ${ }^{29}$ Furthermore, this compound has been used in supercapacitors, electrocatalysts, and Li-ion batteries. ${ }^{30-32} \mathrm{NiCo}_{2} \mathrm{O}_{4}$ has also been used to detect reducing gases, e.g. ethanol, chlorine, carbon monoxide. ${ }^{25,33,34}$

In this study, we report an approach for obtaining $\mathrm{NiCo}_{2} \mathrm{O}_{4}$ hexagonal platelets via a simple and cost-effective urea-assisted co-precipitation method, which are then applied as ozone gas sensors. The co-precipitation method is advantageous for its low processing temperature, high purity, low cost, and controlled morphology compared with most conventional methods. X-ray diffraction and field emission scanning electron microscopy were used to investigate the structural and microstructural properties of $\mathrm{NiCo}_{2} \mathrm{O}_{4}$ hexagonal platelets. Gas sensing experiments were performed at different working

\footnotetext{
${ }^{a}$ São Carlos Institute of Physics, University of São Paulo, CP 369, São Paulo, São Carlo 13560-970, Brazil. E-mail: nirav.joshi1986@gmail.com

${ }^{b}$ LIEC, Institute of Chemistry, São Paulo State University, P.O. Box 355, 14800-900, Araraquara, SP, Brazil

'Department of Energy Science and Technology, Myongji University, Cheoin-gu, Yongin-si, South Korea

${ }^{d}$ Aix Marseille Université, CNRS IM2NP (UMR 7334), FS St Jérôme S152, Marseille, 13397, France

$\dagger$ Electronic supplementary information (ESI) available. See DOI 10.1039/c6ra18384k
}

sensing experiments were performed at different working 
temperatures towards ozone, nitrogen dioxide, and ammonia gas. Impedance spectroscopy measurements were also performed for supporting the ozone gas sensing mechanism of $\mathrm{NiCo}_{2} \mathrm{O}_{4}$ hexagonal platelets.

\section{Experimental}

\subsection{Synthesis of $\mathrm{NiCo}_{2} \mathrm{O}_{4}$ hexagonal platelets}

The synthesis of $\mathrm{NiCo}_{2} \mathrm{O}_{4}$ was accomplished using the ureaassisted co-precipitation method. ${ }^{35}$ To prepare $\mathrm{NiCo}_{2} \mathrm{O}_{4}$ hexagonal platelets, $10 \mathrm{mM}$ of $\mathrm{NiCl}_{2} \cdot 6 \mathrm{H}_{2} \mathrm{O}$ (99.5\% Aldrich), $20 \mathrm{mM}$ of $\mathrm{CoCl}_{2} \cdot 6 \mathrm{H}_{2} \mathrm{O}$ (99.95\% Aldrich) and $100 \mathrm{mM}$ urea (98\% Aldrich) were dissolved in $100 \mathrm{~mL}$ deionized (DI) water, and left under vigorous stirring for $30 \mathrm{~min}$ to form a clear pink color solution. This homogeneous solution was transferred to a glass container, which was kept in an oil bath and maintained for 10 $\mathrm{h}$ at $90{ }^{\circ} \mathrm{C}$, followed by cooling to room temperature. The precipitate powder was washed several times with DI water, ethanol and collected by centrifugation and then dried in a vacuum oven overnight. The powder obtained was annealed for $2 \mathrm{~h}$ at $450{ }^{\circ} \mathrm{C}$ under atmospheric air using a heating rate of 2 ${ }^{\circ} \mathrm{C} \min ^{-1}$ for obtaining crystalline $\mathrm{NiCo}_{2} \mathrm{O}_{4}$ powders. The synthesis of pristine $\mathrm{NiCo}_{2} \mathrm{O}_{4}$ is schematically displayed in Fig. S1 in the ESI. $\dagger$

\subsection{Materials characterization}

The crystalline phase of $\mathrm{NiCo}_{2} \mathrm{O}_{4}$ samples was identified by Xray diffraction (XRD), $\mathrm{CuK} \alpha$ radiation (Rigaku Rotaflex RU200B) in the $2 \theta$ range from 10 to $90^{\circ}$ with a step of $0.02^{\circ}$ and step scanning at $2^{\circ} \min ^{-1}$. The morphology of the as-obtained sample was studied by field emission scanning electron microscopy (FE-SEM, Zeiss Sigma) operating at $5 \mathrm{kV}$ and highresolution transmission electron microscopy (HR-TEM, Philips Tecnai F20 at $200 \mathrm{kV}$ ). Thermo-gravimetric analysis (TGA) analysis was carried out using a thermogravimetric analyzer (Perkin Elmer TGA7) at a scan rate of $10{ }^{\circ} \mathrm{C} \mathrm{min}^{-1}$ in an air atmosphere.

\subsection{Fabrication of $\mathrm{NiCo}_{2} \mathrm{O}_{4}$ sensing film and gas-sensing measurements}

The $\mathrm{NiCo}_{2} \mathrm{O}_{4}$ powders (10 mg) were dispersed in $1 \mathrm{~mL}$ isopropyl alcohol by an ultrasonic cleaner for $30 \mathrm{~min}$ and the suspension was then dropped onto a $\mathrm{SiO}_{2} / \mathrm{Si}$ substrate containing $100 \mathrm{~nm}$ thick Pt electrodes separated by a distance of $50 \mu \mathrm{m}$. The patterning of Pt substrates with photolithographic and lift-off processes reported in our previous reports. ${ }^{19,36,37}$ The substrates were then heated to $80^{\circ} \mathrm{C}$ for $10 \mathrm{~min}$ to evaporate the solvent, followed by calcinations at $350{ }^{\circ} \mathrm{C}$ for $2 \mathrm{~h}$ in an electric furnace in air to stabilize the sample before the gas sensing measurements were performed. The electrical contact and sensor film illustration mentioned in Fig. 1. The sensor sample was inserted into a test chamber for temperature control under different ozone concentrations. The sensor operating temperature $\left(T_{\text {opt. }}\right)$, which varied from $150{ }^{\circ} \mathrm{C}$ to $300{ }^{\circ} \mathrm{C}$, was maintained by external heating. The dc voltage applied was $1 \mathrm{~V}$ while the electrical resistance was measured using a Keithley (model (a)

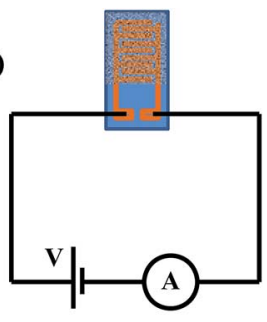

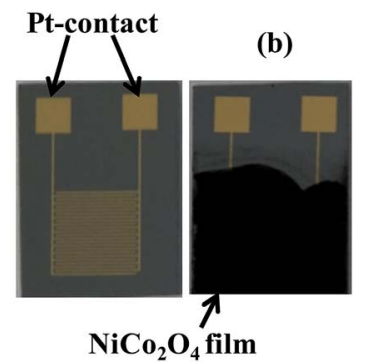

Fig. 1 (a) Schematic illustration of $\mathrm{NiCO}_{2} \mathrm{O}_{4}$-sensor device. (b) Ptinterdigitated $\mathrm{Si} / \mathrm{SiO}_{2}$ substrate and $\mathrm{NiCO}_{2} \mathrm{O}_{4}$ deposited $\mathrm{Si} / \mathrm{SiO}_{2}$ substrate.

6514) electrometer. Dry air was used as both the reference and the carrier gas for all gases, maintaining a constant total flow of $500 \mathrm{sccm}$ via mass flow controllers. The ozone gas was formed by oxidation of oxygen molecules of dry air (500 sccm) with a pen-ray UV lamp (UVP, model $\mathrm{P} / \mathrm{N}$ 90-0004-01), which was calibrated using a gas toxic detector (ATI, model F12) for an $\mathrm{O}_{3}$ level between 28 and 560 ppb (parts-per-billion).

The dry air containing ozone was blown directly onto the sensor placed on a heated holder. Nitrogen dioxide $\left(\mathrm{NO}_{2}\right)$ and ammonia $\left(\mathrm{NH}_{3}\right)$ gas sensing measurements were performed under concentrations varying from 1 to 1000 ppm (parts-permillion). A photograph of the chamber used for gas-sensing experiments is shown in ref. 24. The sensor response (\%) was calculated using eqn (1)

$$
\text { Response }(\%)=\left|\frac{R_{\mathrm{g}}-R_{\mathrm{a}}}{R_{\mathrm{a}}}\right| \times 100
$$

where, $R_{\mathrm{g}}$ and $R_{\mathrm{a}}$ are the electrical resistances of the sensor exposed to target gases and dry air, respectively. The response time was defined as the time required for a change in the sample's electrical resistance to reach $90 \%$ of the initial value when exposed to the target gas. Similarly, the recovery time was defined as the time required for the electrical resistance of the sensor to return to $90 \%$ of the initial value after the target gas has been turned off. During the measurements, the humidity was kept within the range $30-50 \%$ RH (Termo-Higrometro mod.HT-700). Impedance spectroscopy data were obtained with the $\mathrm{NiCo}_{2} \mathrm{O}_{4}$ film using an impedance/gain-phase analyzer (Solartron SI 1260) in the frequency range from $1 \mathrm{~Hz}$ to $1 \mathrm{MHz}$ at an operating temperature of $200{ }^{\circ} \mathrm{C}$.

\section{Results and discussion}

\subsection{Structural and microstructural characterizations}

Fig. 2 displays the XRD pattern of $\mathrm{NiCo}_{2} \mathrm{O}_{4}$ powder annealed for $2 \mathrm{~h}$ at $450{ }^{\circ} \mathrm{C}$, with the XRD peaks indexed as a cubic structure of $\mathrm{NiCo}_{2} \mathrm{O}_{4}$ with $F^{*} 3$ (202) space group (Joint Committee on Powder Diffraction Standards, JCPDS, file no. 20-0781). In order to confirm the crystal structure and composition, Fig. S2 $\uparrow$ shows the XRD pattern of before and after annealing of $\mathrm{NiCo}_{2} \mathrm{O}_{4}$ powder which clearly indicates that before annealing samples is composed of double mixed metal hydroxides and its crystalline 


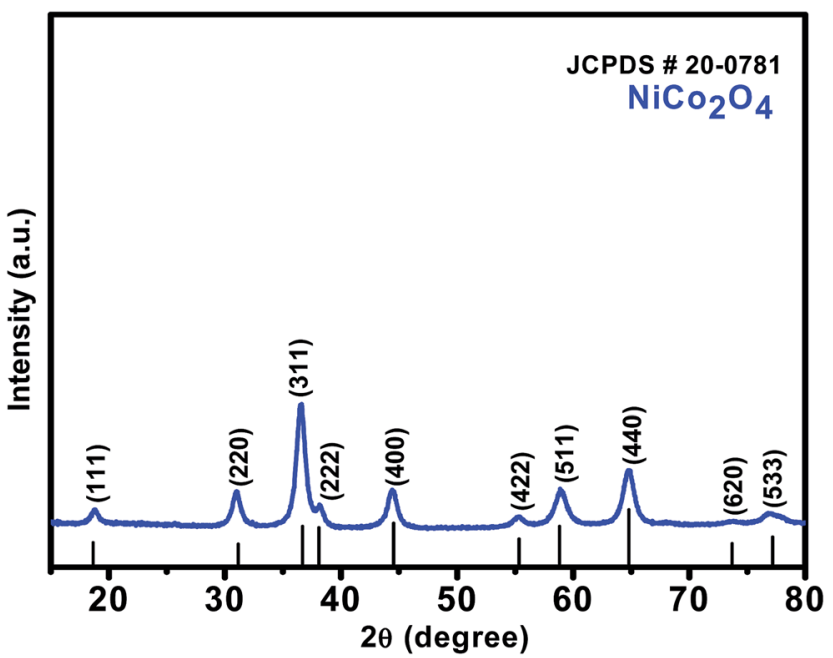

Fig. 2 XRD pattern of $\mathrm{NiCO}_{2} \mathrm{O}_{4}$ annealed at $450{ }^{\circ} \mathrm{C}$ for $2 \mathrm{~h}$ under an ambient atmosphere.

nature which is quite similar to those of $\mathrm{Ni}$ or Co hydroxide (JCPDS no. 46-0605 or 22-0752), which demonstrates the complete decomposition of the precursors to highly pure $\mathrm{NiCo}_{2} \mathrm{O}_{4}$ after annealing. ${ }^{38,39}$ The morphological features of the $\mathrm{NiCo}_{2} \mathrm{O}_{4}$ sample are illustrated in Fig. 3(a and b), where two types of shapes can be seen, viz. 7-8 $\mu \mathrm{m}$ hexagonal platelets and nanoflowers attached on these platelets. Fig. $\mathrm{S} 3 \uparrow$ show the transmission electron microscope (TEM) morphology of the astransformed $\mathrm{NiCo}_{2} \mathrm{O}_{4}$ hexagonal platelets. As can be seen, $\mathrm{NiCo}_{2} \mathrm{O}_{4}$ sample exhibits uniform hexagonal plate morphology.
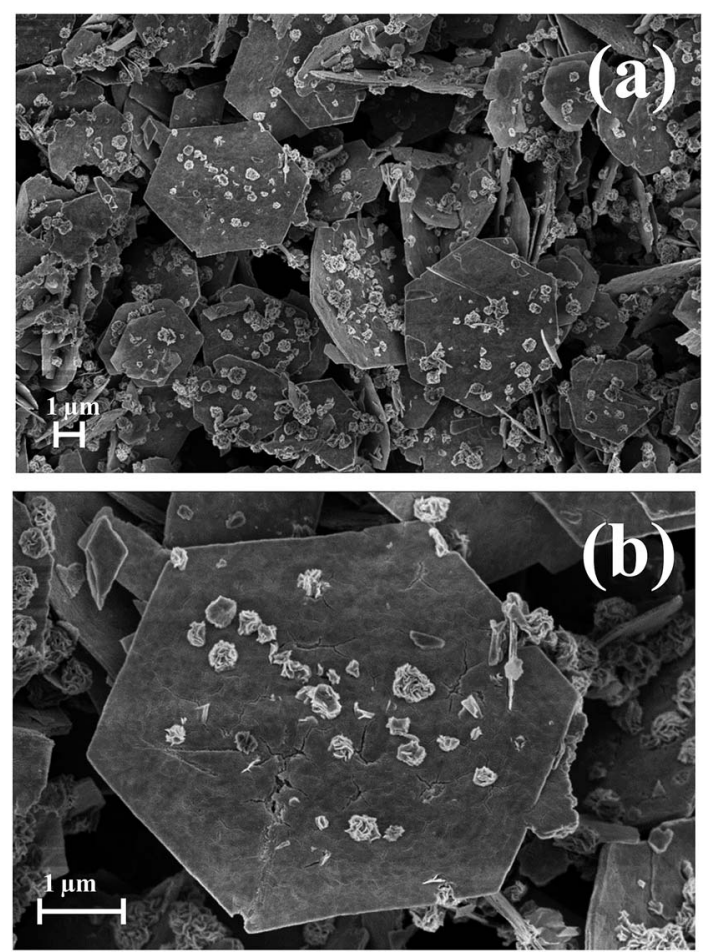

Fig. 3 (a and b) FESEM images of $\mathrm{NiCO}_{2} \mathrm{O}_{4}$ platelets annealed at $450{ }^{\circ} \mathrm{C}$ for $2 \mathrm{~h}$ under an ambient atmosphere.
The selected area electron diffraction (SAED) patterns taken from $\mathrm{NiCo}_{2} \mathrm{O}_{4}$ platelets display hexagonally arranged diffraction spots, suggesting that $\mathrm{NiCO}_{2} \mathrm{O}_{4}$ platelets exist as a single crystal. The measured interplanar distance is $0.47 \mathrm{~nm}$, which matches well to the (111) plane of cubic $\mathrm{NiCo}_{2} \mathrm{O}_{4}$.

The $\mathrm{N}_{2}$ adsorption-desorption isotherms for the $\mathrm{NiCo}_{2} \mathrm{O}_{4}$ sample in Fig. 4 shows a typical hysteresis loop, indicating mesoporous features. The Brunauer-Emmett-Teller (BET) specific surface area was $57.3 \mathrm{~m}^{2} \mathrm{~g}^{-1}$ and the pore volume was $0.228 \mathrm{~m}^{3} \mathrm{~g}^{-1}$. The pore size distribution, derived from desorption data and calculated from the isotherm using the Barrett-Joyner-Halenda (BJH) model (inset in Fig. 4), indicates a pore diameter ranging from 5 to $81 \mathrm{~nm}$, with an average of $15 \mathrm{~nm}^{12,40}$

This hierarchical structure is beneficial to the sensing material because the target molecule gas easily penetrate into the pores, thus leading to a larger analyte/sample contact area and providing interconnected paths that facilitate electron transport and accelerate species diffusion. ${ }^{\mathbf{4 0 - 4 2}}$

In order to understand the weight loss with the temperature during the annealing process, and to determine the annealing temperature of the sample, TGA curve in air was obtained in Fig. S4 $\uparrow$ The total weight loss of $31.5 \%$ upto $430{ }^{\circ} \mathrm{C}$, mainly attributed to loss of residual water and burnout of organic species involved in precursor. Above $430{ }^{\circ} \mathrm{C}$, no obvious weight loss is observed indicating that there is no additional phase or structural change in $\mathrm{NiCo}_{2} \mathrm{O}_{4}$, which is consistent with previous reports. ${ }^{35,43,44}$ Finally, as synthesized material annealed at $450{ }^{\circ} \mathrm{C}$ to get high purity of $\mathrm{NiCo}_{2} \mathrm{O}_{4}$ material.

\subsection{Gas sensing properties}

The electrical response of the $\mathrm{NiCo}_{2} \mathrm{O}_{4}$ sample was investigated at a fixed operating temperature under the exposure of $560 \mathrm{ppb}$ of ozone gas for $1 \mathrm{~min}$ exposure time. Fig. 5 shows that the best sensor response was obtained at $200{ }^{\circ} \mathrm{C}$, which is close to that for traditional gas sensors. ${ }^{7,13,45,46}$ The electrical response of the $\mathrm{NiCo}_{2} \mathrm{O}_{4}$ sample was investigated at a fixed operating

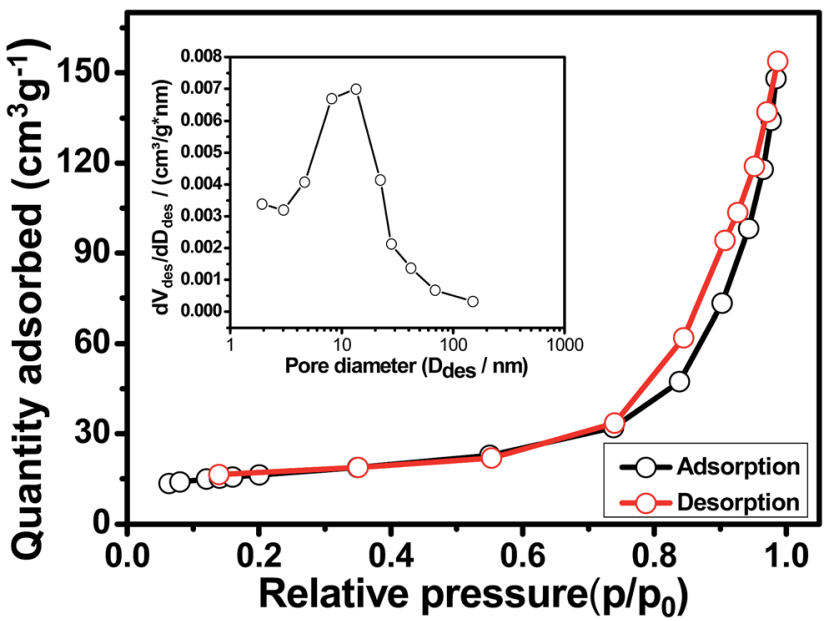

Fig. $4 \mathrm{~N}_{2}$ adsorption-desorption isotherm and pore size distribution (inset) of the $\mathrm{NiCO}_{2} \mathrm{O}_{4}$ platelets. 


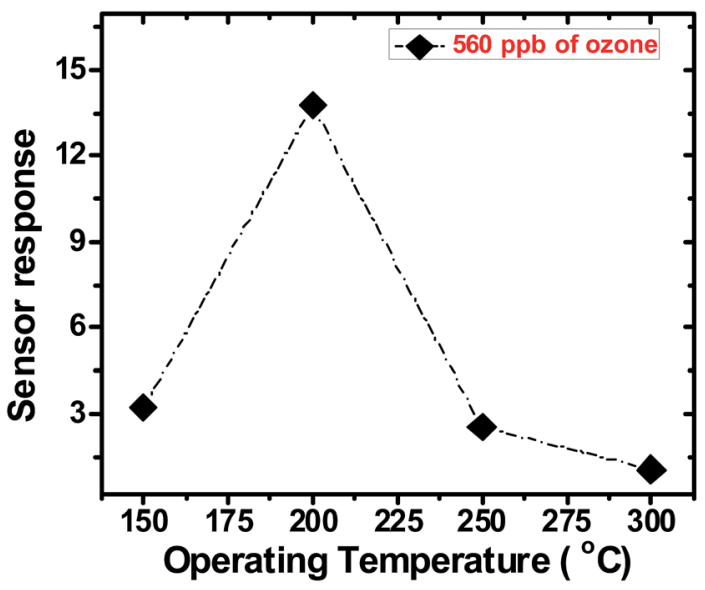

Fig. 5 Gas sensing response of $\mathrm{NiCO}_{2} \mathrm{O}_{4}$ exposed to $560 \mathrm{ppb} \mathrm{O}_{3}$ at different operating temperatures.

temperature of $200{ }^{\circ} \mathrm{C}$ under the exposure of $80 \mathrm{ppb}$ of ozone gas at different times $(0.5,1.0$ and $5.0 \mathrm{~min})$. As displayed in Fig. S5, $\uparrow$ the sample was sensitive to ozone gas even for the shortest exposure time, with no evidence of saturation upon increasing the time. Additionally, we emphasize that with $\mathrm{NiCo}_{2} \mathrm{O}_{4}$ platelets we could detect the same amount of ozone gas, i.e. $80 \mathrm{ppb}$, at lower temperatures, even at room temperature. However, the recovery time was too long or could even not be reached, as displayed in Fig. S6-S12 in the ESI. $\dagger$

For the remaining experiments, we used the optimized temperature of $200{ }^{\circ} \mathrm{C}$. Fig. 6 shows that the $\mathrm{NiCo}_{2} \mathrm{O}_{4}$ sensor displayed good sensor response in the $28-165 \mathrm{ppb}$ range, with total reversibility and good reproducibility for different ozone levels. As displayed in Fig. S13, $\uparrow$ for each measurement cycle, the sample was exposed for $1 \mathrm{~min}$ with different ozone concentration which indicating a stable and reproducible response. The resistance of the sample decreased upon exposure to the oxidizing gas, indicating a p-type semiconductor behavior. In addition, the response time varied from $32 \mathrm{~s}(28$

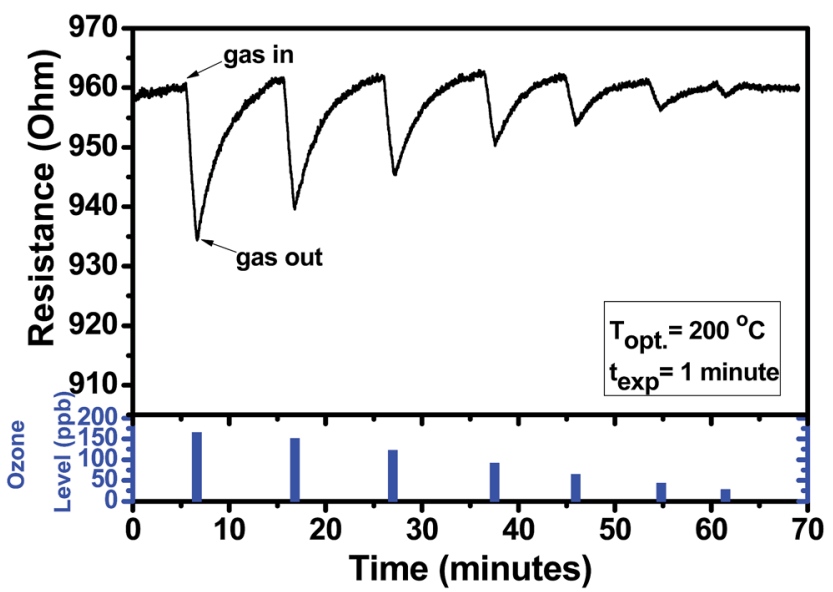

Fig. 6 Ozone gas sensing response for the $\mathrm{NiCO}_{2} \mathrm{O}_{4}$ as a function of the gas level at an operating temperature of $200{ }^{\circ} \mathrm{C}$.
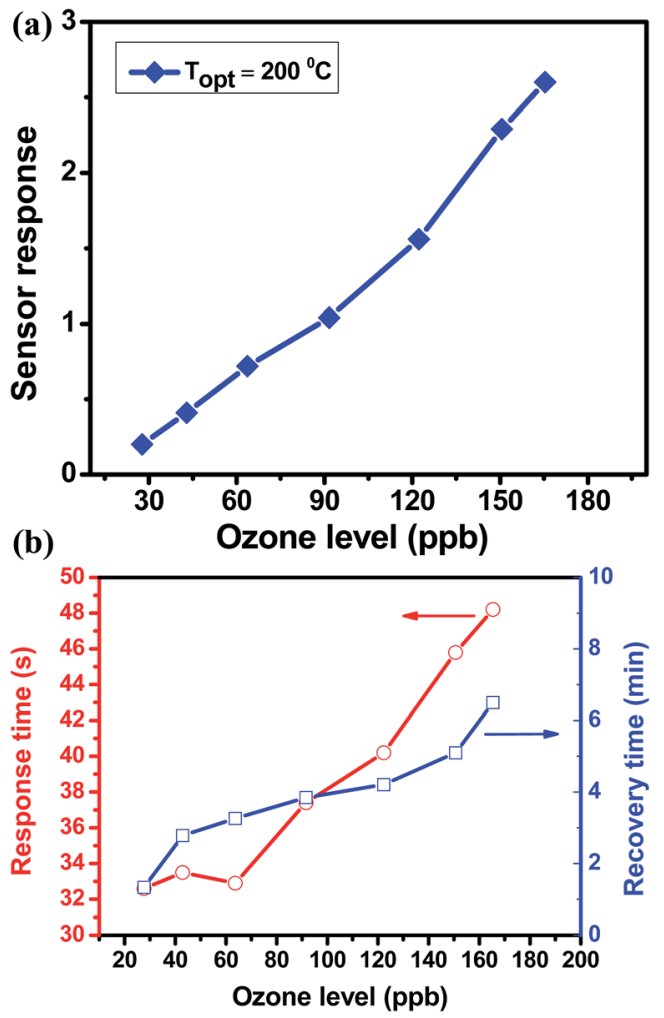

Fig. 7 (a) Sensor response versus gas concentration in the range of 28 to $165 \mathrm{ppb} \mathrm{O}_{3}$. (b) Gas sensing response and recovery time as a function of ozone concentration in the range of 28 to $165 \mathrm{ppb} \mathrm{O}_{3}$ at $200{ }^{\circ} \mathrm{C}$.

$\mathrm{ppb})$ to $48 \mathrm{~s}$ (165 ppb), while the recovery time varied from $1 \mathrm{~min}$ (28 ppb) to $6.5 \mathrm{~min}(165 \mathrm{ppb})$.

Fig. 7(a) shows the sensor response for $\mathrm{NiCo}_{2} \mathrm{O}_{4}$ platelets as a function of ozone concentrations. The response and recovery time is one of the important parameters for toxic gas sensor applications. The response and recovery time as a function of ozone concentrations shows in Fig. 7(b), it can be seen that the response time increases with increasing ozone concentration. The response time increases from 32 to $48 \mathrm{~s}$ while recovery time also increases from 1 to $6.5 \mathrm{~min}$ as the concentration increases from 28 to $165 \mathrm{ppb}$. However at low concentration, more ozone molecules easily interact with adsorbed oxygen ions providing a fast response compared to higher concentration. ${ }^{47}$ In order to verify the selectivity of the sensing materials, the $\mathrm{NiCo}_{2} \mathrm{O}_{4}$ sample was also exposed at $200{ }^{\circ} \mathrm{C}$ to $\mathrm{NH}_{3}$ and $\mathrm{NO}_{2}$, with the results being shown in Fig. $\mathrm{S} 14$ and $\mathrm{S} 15 \dagger$ respectively, while Fig. 8 compares the result for these gases with those of higher ozone concentrations. For the reducing $\mathrm{NH}_{3}$, the resistance increased slightly whereas for the oxidizing $\mathrm{NO}_{2}$ the resistance decreased, as expected. The magnitude of these changes in resistance is much smaller than for ozone, thus confirming that ozone can be detected in a selective manner using $\mathrm{NiCo}_{2} \mathrm{O}_{4}$ platelets.

Table 1 shows a comparison of parameters for ozone sensing with $\mathrm{NiCo}_{2} \mathrm{O}_{4}$ with traditional ozone gas sensors, including $\mathrm{ZnO}, \mathrm{WO}_{3}, \mathrm{SnO}_{2}$, and $\mathrm{In}_{2} \mathrm{O}_{3}$. To our knowledge, the sensor 


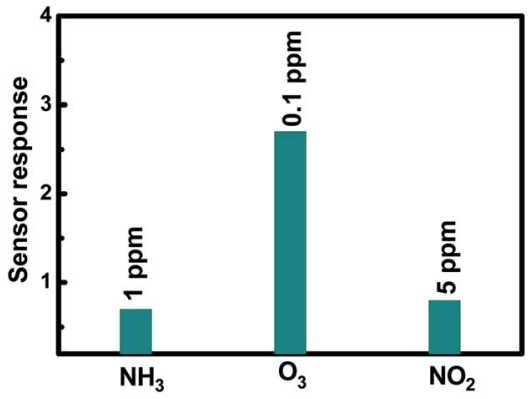

Fig. 8 Selectivity histogram for $\mathrm{NiCO}_{2} \mathrm{O}_{4}$ hexagonal platelets upon exposure to different $\mathrm{NO}_{2}, \mathrm{NH}_{3}$ and ozone concentrations at an operating temperature of $200^{\circ} \mathrm{C}$.

reported here could detect the lowest level of ozone for the temperature with optimized performance.

\subsection{Impedance spectroscopy of $\mathrm{NiCo}_{2} \mathrm{O}_{4}$ hexagonal platelets}

The interaction between $\mathrm{NiCo}_{2} \mathrm{O}_{4}$ sensing material and ozone gas was further investigated using impedance spectroscopy measurements, which may provide information about the different contributions to the sensor response. Fig. 9 shows the Nyquist plots for the $\mathrm{NiCo}_{2} \mathrm{O}_{4}$ film exposed to an air atmosphere, and then to $80 \mathrm{ppb}$ ozone. In both cases, perfect single semicircles are observed from the low to the high-frequency region.

These curves were fitted with an equivalent circuit comprising a resistance $\left(R_{0}\right)$ connected in series with a parallel resistor $\left(R_{1}\right)$-capacitor $\left(C_{1}\right)$ block, as shown in the figure inset. There was good agreement between experimental data and simulated curves using the electrical parameters given in Table 2. As for the physical significance of these components, $R_{0}$ remained unchanged with exposure to either air or ozone atmosphere, and should be attributed to the low resistance effect coming from the conductive-like bulk material. $R_{1}$ and $C_{1}$ are the respective interfacial resistance and capacitance between $\mathrm{NiCo}_{2} \mathrm{O}_{4}$ grains, to be understood here as the particleto-particle contacts, according to the criteria of magnitude order of capacitance. ${ }^{52,53}$ Upon exposure to ozone, $R_{1}$ decreased while $C_{1}$ increased. The interaction of ozone molecules with the sensing material generates lone-pair electrons trapped on the $\mathrm{NiCo}_{2} \mathrm{O}_{4}$ surface, which leads to a holeaccumulating layer. This behavior implied in a reduction of the electrical resistance, and an increase in capacitance of the

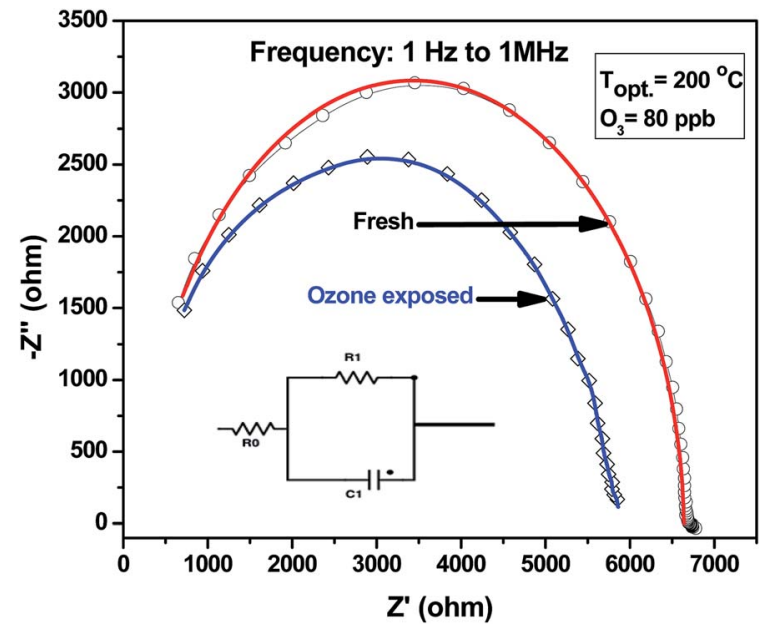

Fig. 9 Impedance spectra of the fresh and ozone exposed $\mathrm{NiCO}_{2} \mathrm{O}_{4}$ film measured at $200{ }^{\circ} \mathrm{C}$. The blue and red colour lines represent the fitting of the spectra using an equivalent circuit.

Table 2 Impedance parameters for a $\mathrm{NiCO}_{2} \mathrm{O}_{4}$ film in the absence, and presence of $80 \mathrm{ppb}$ ozone, from fitting the experimental curves with the equivalent circuit

\begin{tabular}{llll}
\hline Sample & $R_{0}(\Omega)$ & $R_{1}(\Omega)$ & $C_{1}(\mathrm{nF})$ \\
\hline Fresh $\mathrm{NiCo}_{2} \mathrm{O}_{4}$ & 200 & 6413 & 12.73 \\
Ozone exposed- $-\mathrm{NiCo}_{2} \mathrm{O}_{4}$ & 200 & 5451 & 14.11
\end{tabular}

$\mathrm{NiCo}_{2} \mathrm{O}_{4}$ compound. ${ }^{54-56}$ These findings will support the gas sensing mechanism proposed for the $\mathrm{NiCo}_{2} \mathrm{O}_{4}$ compound below.

\subsection{Gas sensing mechanism of $\mathrm{NiCo}_{2} \mathrm{O}_{4}$ hexagonal platelets}

The results above can be rationalized according to the following gas sensing mechanism for $\mathrm{NiCo}_{2} \mathrm{O}_{4}$. Under ambient conditions, oxygen from air is adsorbed on $\mathrm{NiCO}_{2} \mathrm{O}_{4}$, with surface states thus being created. ${ }^{54,57}$ These surface states allow electrons to be excited from the valence band, and therefore additional holes are induced in the p-type $\mathrm{NiCo}_{2} \mathrm{O}_{4}$ grains. ${ }^{58}$

Detection of oxidizing gases on a p-type sensor material is known to arise from surface adsorption of gas molecules, which leads to a hole accumulation layer (HAL) near the surface because of electrostatic interaction between oppositely charged

Table 1 Comparison of ozone gas sensor parameters for a $\mathrm{NiCO}_{2} \mathrm{O}_{4}$ compound with other metal oxides

\begin{tabular}{|c|c|c|c|c|c|c|}
\hline $\mathrm{ZnO}$ & Hydrothermal method & $60-1000$ & 250 & $15 \mathrm{~s}$ & $60 \mathrm{~s}$ & 48 \\
\hline $\mathrm{SnO}_{2}$ & Spray pyrolysis deposition & 1000 & 280 & $2 \mathrm{~s}$ & $900 \mathrm{~s}$ & 16 \\
\hline $\mathrm{In}_{2} \mathrm{O}_{3}$ & Sol-gel method and RGTO technique & $30-900$ & 300 & $25 \mathrm{~s}$ & $1200 \mathrm{~s}$ & 50 and 51 \\
\hline $\mathrm{SrTi}_{1-x} \mathrm{Fe}_{x} \mathrm{O}_{3}$ & Polymeric precursor method & $30-1000$ & 260 & $28 \mathrm{~s}$ & $161 \mathrm{~s}$ & 19 \\
\hline
\end{tabular}



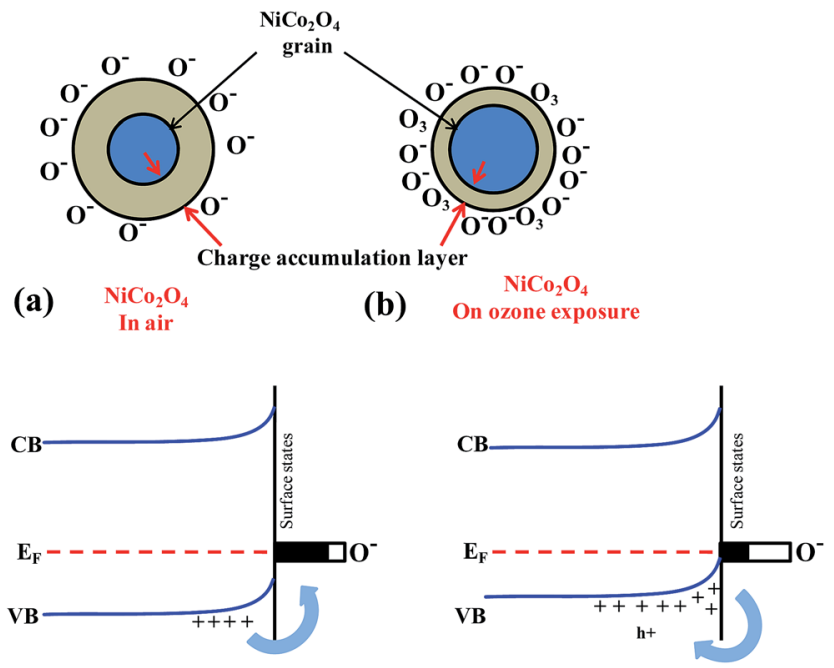

Fig. 10 Schematic illustration representing (a) interaction between oxygen and $\mathrm{NiCO}_{2} \mathrm{O}_{4}$ grain and corresponding energy band diagram; (b) interaction between $\mathrm{O}_{3}$ and $\mathrm{NiCO}_{2} \mathrm{O}_{4}$ grain and corresponding energy band diagram.

species. The latter again establishes the electronic core-shell configuration and induces an increase in the current density. ${ }^{59,60}$ Fig. 10(a and b) depicts such a mechanism where upon exposing $\mathrm{NiCo}_{2} \mathrm{O}_{4}$ to air, atmospheric oxygen is adsorbed in an ionic form at the surface as $\mathrm{O}_{2}{ }^{-}\left(<100{ }^{\circ} \mathrm{C}\right), \mathrm{O}^{-}\left(100-300{ }^{\circ} \mathrm{C}\right)$ and $\mathrm{O}^{2-}\left(>300{ }^{\circ} \mathrm{C}\right)$, which is a function of the operating temperature, as described elsewhere. ${ }^{61}$ For our measurements at $200{ }^{\circ} \mathrm{C}$, adsorbed oxygen is mainly present in the $\mathrm{O}^{-}$form. Fig. 10(a) shows a schematic diagram for the interaction of $\mathrm{O}_{2}$ and $\mathrm{O}_{3}$ gas with $\mathrm{NiCo}_{2} \mathrm{O}_{4}$ grains, along with energy level diagrams. With adsorbed $\mathrm{O}^{-}$species, an accumulation layer is formed at the surface of $\mathrm{NiCo}_{2} \mathrm{O}_{4}$ grains. This is represented in eqn (2)-(5), where adsorption of negatively charged oxygen can generate holes.

$$
\begin{gathered}
\mathrm{O}_{2 \text { (gas) }} \rightarrow \mathrm{O}_{2 \text { (ads.) }} \\
\mathrm{O}_{2 \text { (ads.) }}+\mathrm{e}^{-} \rightarrow \mathrm{O}_{2 \text { (ads.) }}{ }^{-} \\
\mathrm{O}_{2 \text { (ads.) }}{ }^{-}+\mathrm{e}^{-} \rightarrow 2 \mathrm{O}_{\text {(ads.) }}{ }^{-} \\
\mathrm{O}_{\text {(ads.) }}{ }^{-}+\mathrm{e}^{-} \rightarrow \mathrm{O}_{(\text {ads.) }}{ }^{2-}
\end{gathered}
$$

When exposed to oxidizing ozone $\left(\mathrm{O}_{3}\right)$, the $\mathrm{NiCo}_{2} \mathrm{O}_{4}$ surface is covered with adsorbed ozone molecules acting as acceptors, as depicted in Fig. 10(b). This surface trapping of lone-pair of electrons causes band bending, with free holes and increase in hole concentration near the interface. It is the hole accumulated layer that decreases the resistance of $\mathrm{NiCo}_{2} \mathrm{O}_{4}$. The gas sensor response of $\mathrm{NiCo}_{2} \mathrm{O}_{4}$ film for oxidizing gas $\left(\mathrm{O}_{3}\right)$ can be explained by eqn (6). ${ }^{60}$ The reactions between reductive molecules and preadsorbed $\mathrm{O}^{-}$release free electrons and neutralize the holes, which are the majority carriers in p-type $\mathrm{NiCo}_{2} \mathrm{O}_{4}$, as shown in eqn (7).

$$
\begin{gathered}
\mathrm{O}_{3 \text { (gas) }}+\mathrm{e}^{-} \rightarrow \mathrm{O}_{2 \text { (des.) }}+\mathrm{O}_{(\text {ads })}{ }^{-} \\
\mathrm{e}^{-}+\mathrm{h} \rightarrow \text { null }
\end{gathered}
$$

Then, for p-type semiconductors, oxygen adsorption produces an increase in the number of holes in the valence band, which increases conductivity. Note that thermal energy is needed for the reaction between ozone gas molecules and surface adsorbed oxygen species. With increasing temperature, the surface reaction is thermally activated, causing a large decrease in the resistance, which means enhanced response, until saturation occurs and increasing temperature no longer brings increased performance.

\section{Conclusion}

$\mathrm{NiCo}_{2} \mathrm{O}_{4}$ synthesized in one-step approach with a urea-assisted co-precipitation method has been proven excellent for ozone detection with both dc and ac electrical measurements. A low detection level of $28 \mathrm{ppb}$ was achieved at the temperature with optimized performance, below the values in the recent literature. ${ }^{34,62,63}$ The range for detection was from $28-165 \mathrm{ppb}$, with good sensitivity, selectivity and fast response ( $\sim 32 \mathrm{~s})$ and recovery time $(\sim 60 \mathrm{~s})$. The mechanism of detection was found to be based on adsorption of ozone molecules on the $\mathrm{NiCo}_{2} \mathrm{O}_{4}$ surface, which creates a layer of holes that affect the conductivity, as in a p-type semiconductor. The results presented here already demonstrate that $\mathrm{NiCo}_{2} \mathrm{O}_{4}$ is promising for monitoring the environment, and further optimization in ozone sensing may be achieved by analyzing their magnetic and electrical properties, and long-term stability, in addition to the possible use for other reducing and oxidizing gases. In particular, sensitivity can be further enhanced, even reaching sub ppb levels, by varying crystal shapes with tuning by varying parameters such as reaction time and temperature, $\mathrm{pH}$ value, solvent type and concentration, in addition to the use of a catalyst.

\section{Acknowledgements}

The authors are grateful for the financial support from FAPESP (2014/23546-1). Acknowledgments are also due to Angelo L. Gobbi and Maria H. O. Piazzetta for the use of the Microfabrication Laboratory (LMF-20509) facilities to manufacture electrodes (LMF/LNNano-LNLS) Campinas, SP, Brazil.

\section{References}

1 V. Lefèvre, Nanowires: Properties, Synthesis, and Applications, Nova Science Publishers, 2012.

2 S. Guozhen, Recent Pat. Nanotechnol., 2008, 2, 160-168.

3 C. Young-Jin, H. In-Sung, P. Jae-Gwan, C. Kyoung Jin, P. JaeHwan and L. Jong-Heun, Nanotechnology, 2008, 19, 095508.

4 C. Q. Sun, Prog. Solid State Chem., 2007, 35, 1-159.

5 J. Kim and K. Yong, J. Phys. Chem. C, 2011, 115, 7218-7224. 6 A. C. Catto, L. F. Silva, M. I. B. Bernardi, M. S. Li, E. Longo, P. N. Lisboa-Filho, O. R. Nascimento and V. R. Mastelaro, J. Nanopart. Res., 2014, 16, 1-9. 
7 Y. Qin, F. Zhang, Y. Chen, Y. Zhou, J. Li, A. Zhu, Y. Luo, Y. Tian and J. Yang, J. Phys. Chem. C, 2012, 116, 11994-12000.

8 R. Boulmani, M. Bendahan, C. Lambert-Mauriat, M. Gillet and K. Aguir, Sens. Actuators, B, 2007, 125, 622-627.

9 C. S. Rout, M. Hegde and C. N. R. Rao, Sens. Actuators, B, 2008, 128, 488-493.

10 V. Balouria, A. Kumar, S. Samanta, A. Singh, A. K. Debnath, A. Mahajan, R. K. Bedi, D. K. Aswal and S. K. Gupta, Sens. Actuators, B, 2013, 181, 471-478.

11 N. S. Ramgir, I. S. Mulla and K. P. Vijayamohanan, Sens. Actuators, B, 2005, 107, 708-715.

12 T. Wagner, S. Haffer, C. Weinberger, D. Klaus and M. Tiemann, Chem. Soc. Rev., 2013, 42, 4036-4053.

13 C. Cantalini, M. Post, D. Buso, M. Guglielmi and A. Martucci, Sens. Actuators, B, 2005, 108, 184-192.

14 G. Korotcenkov, V. Brinzari, S. H. Han and B. K. Cho, Mater. Chem. Phys., 2016, 175, 188-199.

15 V. Bocci, I. Zanardi and V. Travagli, Am. J. Cardiovasc. Drugs, 2012, 11, 73-82.

16 G. Korotcenkov and B. K. Cho, Sens. Actuators, B, 2012, 161, 28-44.

17 L. Chaves Simoes and M. Simoes, RSC Adv., 2013, 3, 25202533.

18 C. Y. Wang, R. W. Becker, T. Passow, W. Pletschen, K. Köhler, V. Cimalla and O. Ambacher, Sens. Actuators, B, 2011, 152, 235-240.

19 V. R. Mastelaro, S. C. Zílio, L. F. da Silva, P. I. Pelissari, M. I. B. Bernardi, J. Guerin and K. Aguir, Sens. Actuators, B, 2013, 181, 919-924.

20 M. Epifani, S. Capone, R. Rella, P. Siciliano, L. Vasanelli, G. Faglia, P. Nelli and G. Sberveglieri, J. Sol-Gel Sci. Technol., 2003, 26, 741-744.

21 G. Korotcenkov and B. K. Cho, Sens. Actuators, B, 2009, 142, 321-330.

22 K. Aguir, C. Lemire and D. B. B. Lollman, Sens. Actuators, B, 2002, 84, 1-5.

23 L. F. da Silva, A. C. Catto, W. Avansi, L. S. Cavalcante, J. Andres, K. Aguir, V. R. Mastelaro and E. Longo, Nanoscale, 2014, 6, 4058-4062.

24 L. F. da Silva, V. R. Mastelaro, A. C. Catto, C. A. Escanhoela Jr, S. Bernardini, S. C. Zílio, E. Longo and K. Aguir, J. Alloys Compd., 2015, 638, 374-379.

25 F. Iacomi, G. Calin, C. Scarlat, M. Irimia, C. Doroftei, M. Dobromir, G. G. Rusu, N. Iftimie and A. V. Sandu, Thin Solid Films, 2011, 520, 651-655.

26 J. Li, S. Xiong, Y. Liu, Z. Ju and Y. Qian, ACS Appl. Mater. Interfaces, 2013, 5, 981-988.

27 X. H. Huang, J. P. Tu, X. H. Xia, X. L. Wang and J. Y. Xiang, Electrochem. Commun., 2008, 10, 1288-1290.

28 J. Liu, C. Liu, Y. Wan, W. Liu, Z. Ma, S. Ji, J. Wang, Y. Zhou, P. Hodgson and Y. Li, CrystEngComm, 2013, 15, 1578-1585.

29 S. Khalid, C. Cao, L. Wang and Y. Zhu, Sci. Rep., 2016, 6, 22699.

30 X.-Y. Yu, X.-Z. Yao, T. Luo, Y. Jia, J.-H. Liu and X.-J. Huang, ACS Appl. Mater. Interfaces, 2014, 6, 3689-3695.

31 Q. Wang, X. Wang, B. Liu, G. Yu, X. Hou, D. Chen and G. Shen, J. Mater. Chem. A, 2013, 1, 2468-2473.
32 Y. Zhu, X. Ji, Z. Wu, W. Song, H. Hou, Z. Wu, X. He, Q. Chen and C. E. Banks, J. Power Sources, 2014, 267, 888-900.

33 G.-Y. Zhang, B. Guo and J. Chen, Sens. Actuators, B, 2006, 114, 402-409.

34 G. Korotcenkov, V. Brinzari and B. K. Cho, J. Sens., 2016, 2016, 31.

35 H. S. Jadhav, R. S. Kalubarme, C.-N. Park, J. Kim and C.-J. Park, Nanoscale, 2014, 6, 10071-10076.

36 S. Thirumalairajan, V. R. Mastelaro and C. A. Escanhoela, ACS Appl. Mater. Interfaces, 2014, 6, 21739-21749.

37 P. A. Raymundo-Pereira, F. M. Shimizu, D. Coelho, M. H. O. Piazzeta, A. L. Gobbi, S. A. S. Machado and O. N. Oliveira Jr, Biosens. Bioelectron., 2016, 86, 369-376.

38 Y. Li, M. Zhou, X. Cui, Y. Yang, P. Xiao, L. Cao and Y. Zhang, Electrochim. Acta, 2015, 161, 137-143.

39 G. Chen, Y. Gao and H. Zhang, RSC Adv., 2016, 6, 3048830497.

40 X. Zhou, G. Chen, J. Tang, Y. Ren and J. Yang, J. Power Sources, 2015, 299, 97-103.

41 L. Hu, L. Wu, M. Liao, X. Hu and X. Fang, Adv. Funct. Mater., 2012, 22, 998-1004.

42 J.-S. Hu, L.-S. Zhong, W.-G. Song and L.-J. Wan, Adv. Mater., 2008, 20, 2977-2982.

43 J. Liang, Z. Fan, S. Chen, S. Ding and G. Yang, Chem. Mater., 2014, 26, 4354-4360.

44 Y. Lei, J. Li, Y. Wang, L. Gu, Y. Chang, H. Yuan and D. Xiao, ACS Appl. Mater. Interfaces, 2014, 6, 1773-1780.

45 C.-H. Wu, G.-J. Jiang, K.-W. Chang, C.-W. Lin and K.-L. Chen, Sens. Actuators, B, 2015, 211, 354-358.

46 M. Acuautla, S. Bernardini, M. Bendahan and E. Pietri, Sens. Actuators, B, 2014, 203, 602-611.

47 V. N. Mishra and R. P. Agarwal, Microelectron. J., 1998, 29, 861-874.

48 A. C. Catto, L. F. da Silva, C. Ribeiro, S. Bernardini, K. Aguir, E. Longo and V. R. Mastelaro, $R S C A d v$., 2015, 5, 1952819533.

49 M. Bendahan, R. Boulmani, J. L. Seguin and K. Aguir, Sens. Actuators, B, 2004, 100, 320-324.

50 C. Baratto, M. Ferroni, G. Faglia and G. Sberveglieri, Sens. Actuators, B, 2006, 118, 221-225.

51 A. Gurlo, N. Barsan, U. Weimar, M. Ivanovskaya, A. Taurino and P. Siciliano, Chem. Mater., 2003, 15, 4377-4383.

52 J. R. Macdonald and W. R. Kenan, Impedance Spectroscopy: Emphasizing Solid Materials and Systems, Wiley, 1987.

53 A. Delgado, M. F. García-Sánchez, J.-C. M'Peko, A. R. RuizSalvador, G. Rodríguez-Gattorno, Y. Echevarría and F. Fernández-Gutierrez, J. Chem. Educ., 2003, 80, 1062.

54 N. Joshi, V. Saxena, A. Singh, S. P. Koiry, A. K. Debnath, M. M. Chehimi, D. K. Aswal and S. K. Gupta, Sens. Actuators, B, 2014, 200, 227-234.

55 D. K. Bandgar, S. T. Navale, S. R. Nalage, R. S. Mane, F. J. Stadler, D. K. Aswal, S. K. Gupta and V. B. Patil, J. Mater. Chem. C, 2015, 3, 9461-9468.

56 S. T. Navale, D. K. Bandgar, M. A. Chougule and V. B. Patil, RSC Adv., 2015, 5, 6518-6527.

57 H. Yoon, J.-Y. Hong and J. Jang, Small, 2007, 3, 1774-1783. 
58 D. K. Aswal and S. K. Gupta, Science and Technology of Chemiresistor Gas Sensors, Nova Science Publishers, 2007.

59 H.-J. Kim and J.-H. Lee, Sens. Actuators, B, 2014, 192, 607627.

60 S. Maeng, S.-W. Kim, D.-H. Lee, S.-E. Moon, K.-C. Kim and A. Maiti, ACS Appl. Mater. Interfaces, 2014, 6, 357-363.

61 M. Bender, E. Gagaoudakis, E. Douloufakis, E. Natsakou, N. Katsarakis, V. Cimalla, G. Kiriakidis, E. Fortunato,
P. Nunes, A. Marques and R. Martins, Thin Solid Films, 2002, 418, 45-50.

62 L. S. R. Rocha, C. R. Foschini, C. C. Silva, E. Longo and A. Z. Simões, Ceram. Int., 2016, 42, 4539-4545.

63 S. Thirumalairajan and V. R. Mastelaro, Sens. Actuators, B, 2016, 223, 138-148. 